\title{
Article \\ Enhanced Heat-Electric Conversion via Photonic-Assisted Radiative Cooling
}

\author{
Jeng-Yi Lee ${ }^{1} \mathbb{D}$, Chih-Ming Wang ${ }^{2, *(\mathbb{D}}$, Chieh-Lun Chi ${ }^{1}$, Sheng-Rui Wu ${ }^{2}$, Ya-Xun Lin ${ }^{3}$, Mao-Kuo Wei ${ }^{3}$ \\ and Chu-Hsuan Lin 1 ,*
}

check for updates

Citation: Lee, J.-Y.; Wang, C.-M.; Chi, C.-L.; Wu, S.-R.; Lin, Y.-X.; Wei, M.-K.; Lin, C.-H. Enhanced Heat-Electric Conversion via Photonic-Assisted Radiative Cooling. Nanomaterials 2021, 11, 983. https://doi.org/ 10.3390/nano11040983

Academic Editor: Luis Morellón

Received: 12 March 2021

Accepted: 7 April 2021

Published: 11 April 2021

Publisher's Note: MDPI stays neutral with regard to jurisdictional claims in published maps and institutional affiliations.

Copyright: (c) 2021 by the authors. Licensee MDPI, Basel, Switzerland. This article is an open access article distributed under the terms and conditions of the Creative Commons Attribution (CC BY) license (https:/ / creativecommons.org/licenses/by/ $4.0 /)$.
1 Department of Opto-Electronic Engineering, National Dong Hwa University, Hualien 97401, Taiwan; jengyilee@gms.ndhu.edu.tw (J.-Y.L.); 610725011@gms.ndhu.edu.tw (C.-L.C.)

2 Department of Optics and Photonics, National Central University, Taoyuan 32001, Taiwan; 410325015@gms.ndhu.edu.tw

3 Department of Materials Science and Engineering, National Dong Hwa University, Hualien 97401, Taiwan; yaxunlin@gapp.nthu.edu.tw (Y.-X.L.); mkwei@gms.ndhu.edu.tw (M.-K.W.)

* Correspondence: cmwang@cc.ncu.edu.tw (C.-M.W.); chlin0109@gms.ndhu.edu.tw (C.-H.L.); Tel.: +886-3-4227151 (ext. 25248) (C.-M.W.); +886-3-8903188 (C.-H.L.)

\begin{abstract}
In this paper, an inorganic polymer composite film is proposed as an effective radiative cooling device. The inherent absorption is enhanced by choosing an appropriately sized $\mathrm{SiO}_{2}$ microsphere with a diameter of $6 \mu \mathrm{m}$. The overall absorption at the transparent window of the atmosphere is higher than $90 \%$, as the concentration of $\mathrm{SiO}_{2}-\mathrm{PMMA}$ composite is $35 \mathrm{wt} \%$. As a result, an effective radiative device is made by a spin coating process. Moreover, the device is stacked on the cold side of a thermoelectric generator chip. It is found that the temperature gradient can be increased via the effective radiative cooling process. An enhanced Seebeck effect is observed, and the corresponding output current can be enhanced 1.67-fold via the photonic-assisted radiative cooling.
\end{abstract}

Keywords: radiative cooling; Seebeck effect; thermoelectric generator (TEG)

\section{Introduction}

At present, most of the main energy sources convert petrochemical or nuclear energy into kinetic energy, which is then converted to electric power by a bulky mechanical electric generator. Photovoltaic (PV) energy harvesting technology directly converts solar power to electricity without an electric generator. Moreover, owing to the compact size of the PV panel compared to the bulky mechanical electric generator, versatile applications that traditional electricity systems cannot offer emerge. Consequently, converting ambient energy, for example, solar power and a heat source, to electric power to operate low-power electronic devices or replace small batteries is an alternative potential application of green energy technology via a small power generation device. Nevertheless, the theoretical efficiency of a PV cell is limited by the matching spectrum between the solar and solar cell. Consequently, some energy up-conversion concepts, such as thermophotovoltaic [1] and multiphoton absorption [2], have been proposed to convert the long-wavelength energy to short-wavelength energy in order to improve the matching spectrum for a higher PV conversion efficiency. Thermal-to-electricity conversion technology harvests heat via a thermoelectric generator (TEG) chip with a size similar to a PV cell. Compared to commonly used PV energy harvesting technology, thermal-to-electricity conversion is not limited by the weather. Therefore, a TEG is more suitable and stable than a PV cell to harvest ambient energy.

In 1977, Bartoli et al. first demonstrated cooling technology based on thermal radiation [3]. Radiative cooling is the natural heat transportation process through which objects shed heat in the form of radiation. All objects at room temperature emit heat via radiation. As the emission wavelength of an object is tuned to be at the transparency 
window $(8 \mu \mathrm{m}$ to $14 \mu \mathrm{m})$ of the atmosphere, the heat can radiate to the cold sink of outer space via the transparency window of the atmosphere. This technology is called radiative cooling. A number of works aimed at designing various photonic and plasmonic structures for radiative cooling applications have also been proposed [4-8]. For example, based on the metal-dielectric photonic structure, E. Rephaeli et al. first demonstrated a net cooling power in excess of $100 \mathrm{~W} / \mathrm{m}^{2}$ at ambient temperature [4]. A.P. Raman et al. experimentally demonstrated that the $\mathrm{HfO}_{2} / \mathrm{SiO}_{2}$ multilayer photonic radiative cooler cools to $4.9{ }^{\circ} \mathrm{C}$ below the ambient temperature under direct sunlight illumination and $19.5^{\circ} \mathrm{C}$ lower than the ambient temperature at night [9]. By using a visibly transparent silica photonic crystal, L. Zhu et al. experimentally demonstrated that the temperature of a silicon absorber under sunlight can be reduced by $13^{\circ} \mathrm{C}$ due to radiative cooling [10].

For practical applications, in particular, low-cost passive radiative cooling with a large device area is of much interest. Therefore, owing to the relatively simple and lowcost fabrication process, radiative cooling based on micro-/nanoparticles attracts a great deal of research interest. For example, radiative coolers based on $\mathrm{SiC} / \mathrm{SiO}_{2}$ nanoparticle composites [5], $\mathrm{SiO}_{2}$ particle embedded poly(4-methyl-1-pentyne) (TPX) film [7], and $\mathrm{SiO}_{2}$ microsphere white paint [11] are all easy to produce at a low cost and present the capability to exceed $10^{\circ} \mathrm{C}$ below ambient temperature.

\section{Materials and Methods}

We know that the sun is the largest provider of green energy. When we harvest solar energy, we need a device to absorb solar light and then convert the solar energy to different forms of energy - for example, converting solar energy to electric potential such as solar cells, converting solar energy to chemical potential, and converting solar to thermal energy. Regardless, as we harvest solar energy, conversion loss is unavoidable, and heat is eventually generated, which means that the Earth will be heated. Consequently, the surfaces of current high-efficiency solar panels are black to absorb a wide spectral range of sunlight. However, only a fraction (usually below $20 \%$ for commercially available solar panels) of this incoming energy is converted to electric power. The rest is returned to the environment as heat. The solar panels are usually much darker than the ground. As a result, the solar panels absorb a great deal of additional solar energy, and the Earth is thus heated.

In this paper, we would like to demonstrate a method to harvest the ambient energy by returning the heat to outer and generating electric energy. The concept of the proposed device is shown in Figure 1. Radiative cooling technology is utilized to create a temperature gradient on a TEG chip by radiating the ambient heat to outer space. Via the photonicassisted radiative cooling, the enhancement of the Seebeck effect of the TEG chip is observed. The heat will be sent to outer space but will not be absorbed. Thus, we are able to harvest an inexhaustible supply of ambient heat energy. Therefore, the Earth will not be heated. We believe that our proposed method is greener than the current green energy.

The device consists of a TEG chip and a passive radiative cooling device. The TEG chip with a device area of $15 \mathrm{~mm} \times 15 \mathrm{~mm}$ is composed of two dissimilar thermoelectric materials, a $p$-type and an $n$-type semiconductor, connected at their ends. The temperature gradient in the thermoelectric material leads to free carrier diffusion, so that a voltage difference between the hot and cold sides of the TEG can be created. The corresponding power, $P_{T E G}$, delivered to an external load is [12]:

$$
P_{T E G}=\frac{S^{2} \Delta T^{2} R_{e}}{\left(R_{T E}+R_{e}\right)^{2}}
$$

where $R_{T E}$ and $R_{e}$ are the electric resistance of the TEG and the external load resistance, respectively. $S$ is the Seebeck coefficient, and $\Delta T$ is the temperature difference across the TEG. It can be seen that the output power is proportional to $\Delta T^{2}$. Therefore, we can increase the power that is driven from the TEG by maximizing the temperature gradient. Here, we utilize a passive radiative cooling device to direct the environmental heat toward outer 
space so that the temperature gradient between the hot and cold sides of the TEG can be increased. Consequently, we are able to enhance the output power of the TEG.

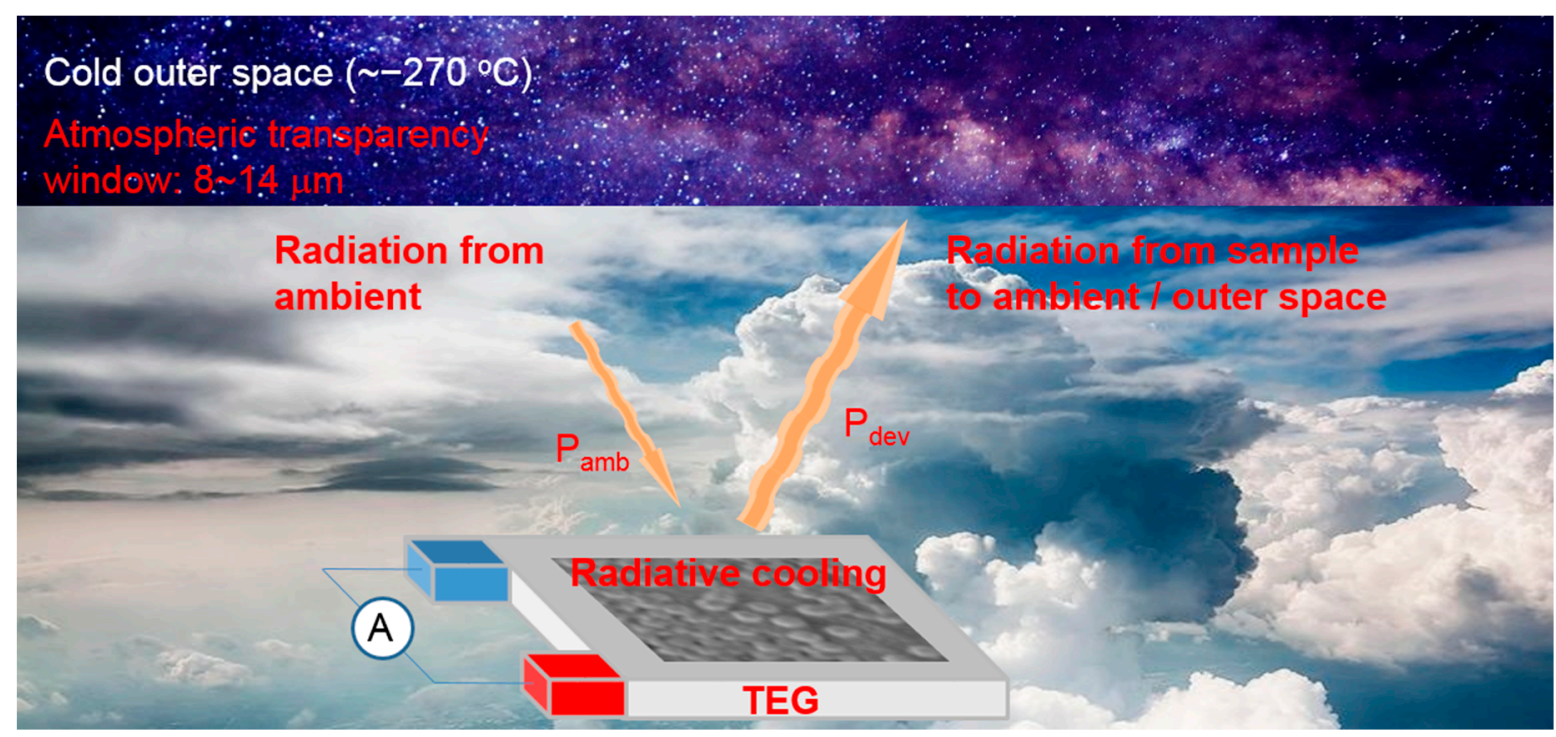

Figure 1. Conceptual schematic of the proposed device for harvesting ambient energy via passive radiative cooling device.

Recently, inorganic polymer nanocomposites have attracted significant interest as emerging materials due to their unique combination of properties as compared to pure polymers $[13,14]$. The physical properties of the composites can be easily modified via changing the compositions and concentrations. Here, we selected $\mathrm{SiO}_{2}-\mathrm{PMMA}_{\mathrm{C}}$ composites to fabricate a radiative cooling device. The absorption of the nanocomposite film can be tuned by simply modifying the concentration of $\mathrm{SiO}_{2} \cdot \mathrm{SiO}_{2}$ nanoparticles were dispersed and mixed in PMMA for nine different concentrations $(5,10,15,20,25,30,35,40$, and $45 \mathrm{wt} \%$ ). $\mathrm{The} \mathrm{SiO}_{2}$ microparticles are commercially available. They were purchased from Promagic Technology Co., Ltd. (Taoyuan, Taiwan). The product name was PMG-5506. The average diameter of the $\mathrm{SiO}_{2}$ particles was $6 \mu \mathrm{m}$. The $\mathrm{SiO}_{2}-\mathrm{PMMA}$ composite was then spin-coated onto a $\mathrm{Cu}$ substrate. The reason that we chose $\mathrm{Cu}$ was the possibility of achieving heat conduction between the radiative cooling film and the cold side of the TEG chip. A side view of the scanning electron microscope (SEM) photograph of the spincoated $\mathrm{SiO}_{2}-\mathrm{PMMA}$ composite film is provided in Figure 2. The PMMA weight percent was $9 \mathrm{wt} \%$. Under this concentration, the $\mathrm{SiO}_{2}$ particles can be successfully adhered. The optical properties mainly depend on the $\mathrm{SiO}_{2}$ microsphere. Figure 2a-i indicate the weight percent concentration of the $\mathrm{SiO}_{2}$ particle, which gradually increased from $5 \mathrm{wt} \%$ to $45 \mathrm{wt} \%$. It can be seen that the $\mathrm{SiO}_{2}$ dispersed uniformly, and most of the area was covered by a single layer of $\mathrm{SiO}_{2}$ particles as the $\mathrm{SiO}_{2}$ concentration ranged from $15 \mathrm{wt} \%$ to $25 \mathrm{wt} \%$. A higher weight percentage of $\mathrm{SiO}_{2}$ leads to a higher filling ratio. Consequently, a higher filling ratio of $\mathrm{SiO}_{2}$ spheres leads to higher absorption, which will be discussed in the following modeling section. When the $\mathrm{SiO}_{2}$ concentration is lower than $10 \mathrm{wt} \%$, the substrate is not fully covered by $\mathrm{SiO}_{2}$ particles. When the $\mathrm{SiO}_{2}$ concentration is $30 \mathrm{wt} \%$ and $35 \mathrm{wt} \%$, it presents two layers of closely packed $\mathrm{SiO}_{2}$ particles. When the $\mathrm{SiO}_{2}$ concentration is higher than $40 \mathrm{wt} \%$, it presents multiple layers of closely packed $\mathrm{SiO}_{2}$ particles.

For an effective radiative cooling device, it is necessary to enhance the emissivity at the transparent window of the atmosphere. The heat at this spectral range can effectively radiate to the cold sink of outer space so that the heat can be directed to outer space. Additionally, it is necessary to suppress the absorption of the sideband, specifically the solar spectral range. The sideband refers to the spectral range that is outside of the transparent window of the atmosphere. By doing this, the device will emit the heat into the environment without absorbing it back again. The absorption spectrum of an ideal radiative cooling 
device is $100 \%$ at the transparent window of the atmosphere and is $0 \%$ at all others [15]. Both the PMMA and $\mathrm{SiO}_{2}$ are transparent, with a broad bandwidth, as is the absorption at the transparent window of the atmosphere. Additionally, the $\mathrm{SiO}_{2}$ supports both dipoleallowed transverse optical (TO) vibration and longitudinal optical (LO) bond-bending vibration modes at $9 \mu \mathrm{m}$ and $12 \mu \mathrm{m}$, respectively. The phonon absorption bandwidth of $\mathrm{SiO}_{2}$ is fully covered by the spectral range of the transparent window. Therefore, $\mathrm{SiO}_{2}-$ PMMA inorganic polymer nanocomposites are a potential candidate for radiative cooling applications because of the transparency at the visible range and the high absorptivity at the transparent window. For lower absorption in the visible spectral range, an Al substrate might be a better choice than $\mathrm{Cu}$. However, the heat conduction of $\mathrm{Cu}$ is much better than that of Al. Therefore, a trade-off exists between the reflectivity and conductivity of a metal substrate.

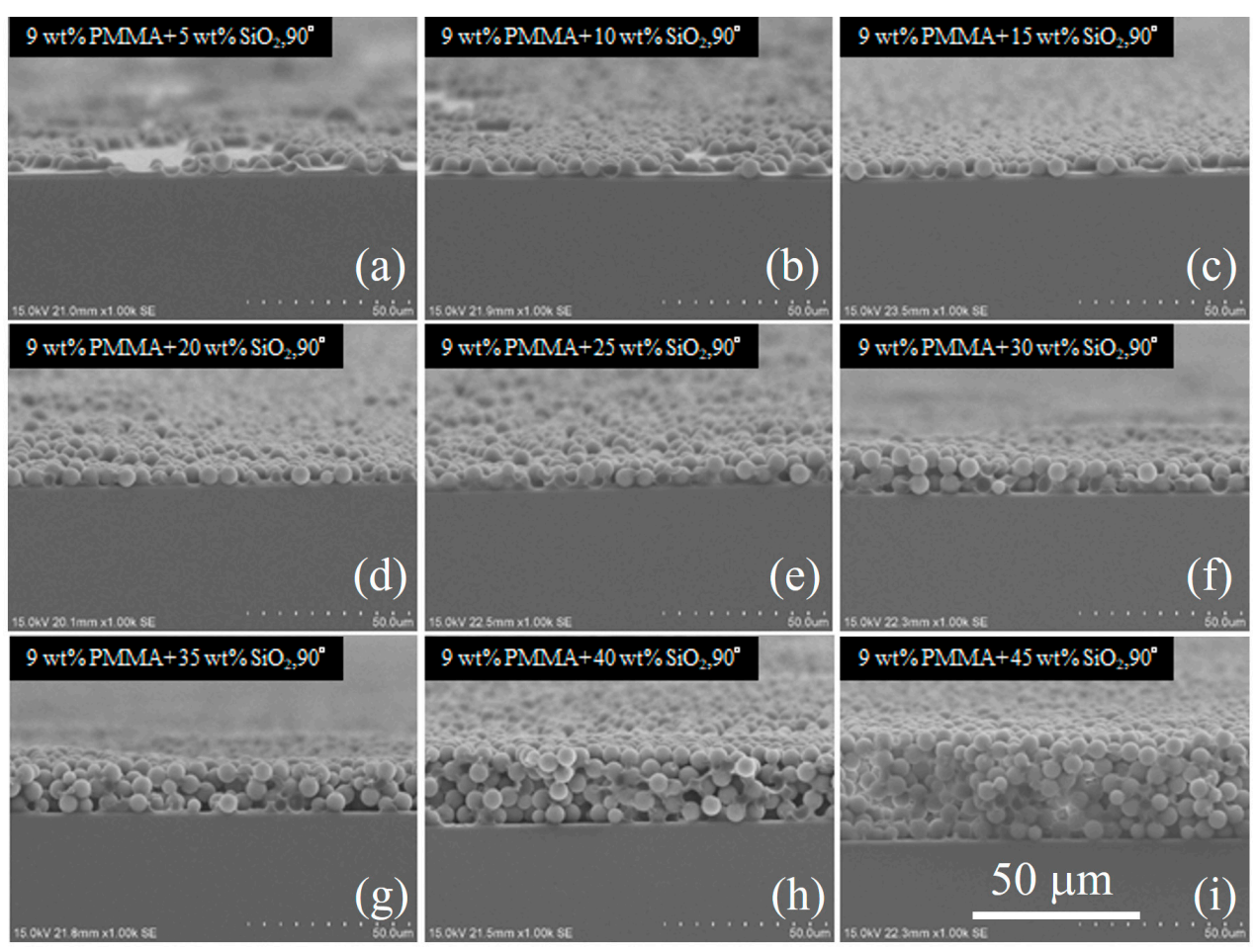

Figure 2. Side-view of the SEM photograph of the fabricated $\mathrm{SiO}_{2}-\mathrm{PMMA}$ composite film with a total area of $15 \mathrm{~mm} \times 15 \mathrm{~mm}$. (a-i) indicate the weight percent concentration of $\mathrm{SiO}_{2}$ particles gradually increased from $5 \mathrm{wt} \%$ to $45 \mathrm{wt} \%$.

As mentioned, the diameter of the utilized $\mathrm{SiO}_{2}$ particles is $6 \mu \mathrm{m}$. As the spin-coated $\mathrm{SiO}_{2}$ particles are closely packed, the periodicity of the $\mathrm{SiO}_{2}$ particle array is identical to its diameter. At this time, according to classic diffraction theory, the diffraction angle is close to $90^{\circ}$ for normally incident light with the wavelength of the transparent window of the atmosphere. Additionally, the Fourier transformation of the $\mathrm{SiO}_{2}$ sphere is a ripple-like function consisting of spherical Hankel functions [16]. As spherical particles are closely packed, the lattice is hexagonal. As we consider the $\Gamma$ point of the reciprocal space, the period $(\Lambda)$ is the diameter of the $\mathrm{SiO}_{2}$ microparticles. The period, $6 \mu \mathrm{m}$, is approximately half of the transparent window's wavelength $(8-14 \mu \mathrm{m})$. Under this condition, all the diffraction orders in free space are evanescent. However, there is still a possibility that the light can be coupled within the closely packed $\mathrm{SiO}_{2}$ microparticles. At this time, the absorption path of the coupled light can be dramatically prolonged, and the emissivity can be thus increased. This phenomenon is called the guided-mode resonance effect [17].

The top-view of the SEM photograph of the fabricated $\mathrm{SiO}_{2}-\mathrm{PMMA}$ composite film for the $\mathrm{SiO}_{2}$ particle with different weight percent concentrations is provided in Figure 3 . 
As shown in Figure $3 \mathrm{a}$, for $15 \mathrm{wt} \%$, some areas of the spin-coated $\mathrm{SiO}_{2}-\mathrm{PMMA}$ composite are not closely packed. As the weight percent concentration of the $\mathrm{SiO}_{2}$ particle is $20 \mathrm{wt} \%$ (Figure 3b), the SEM photograph reveals that the $\mathrm{SiO}_{2}$ microparticles are closely packed, which is consistent with the side-view SEM. For $25 \mathrm{wt} \%$ (Figure 3c), it can be seen that the $\mathrm{SiO}_{2}$ stacks as a multilayer structure.
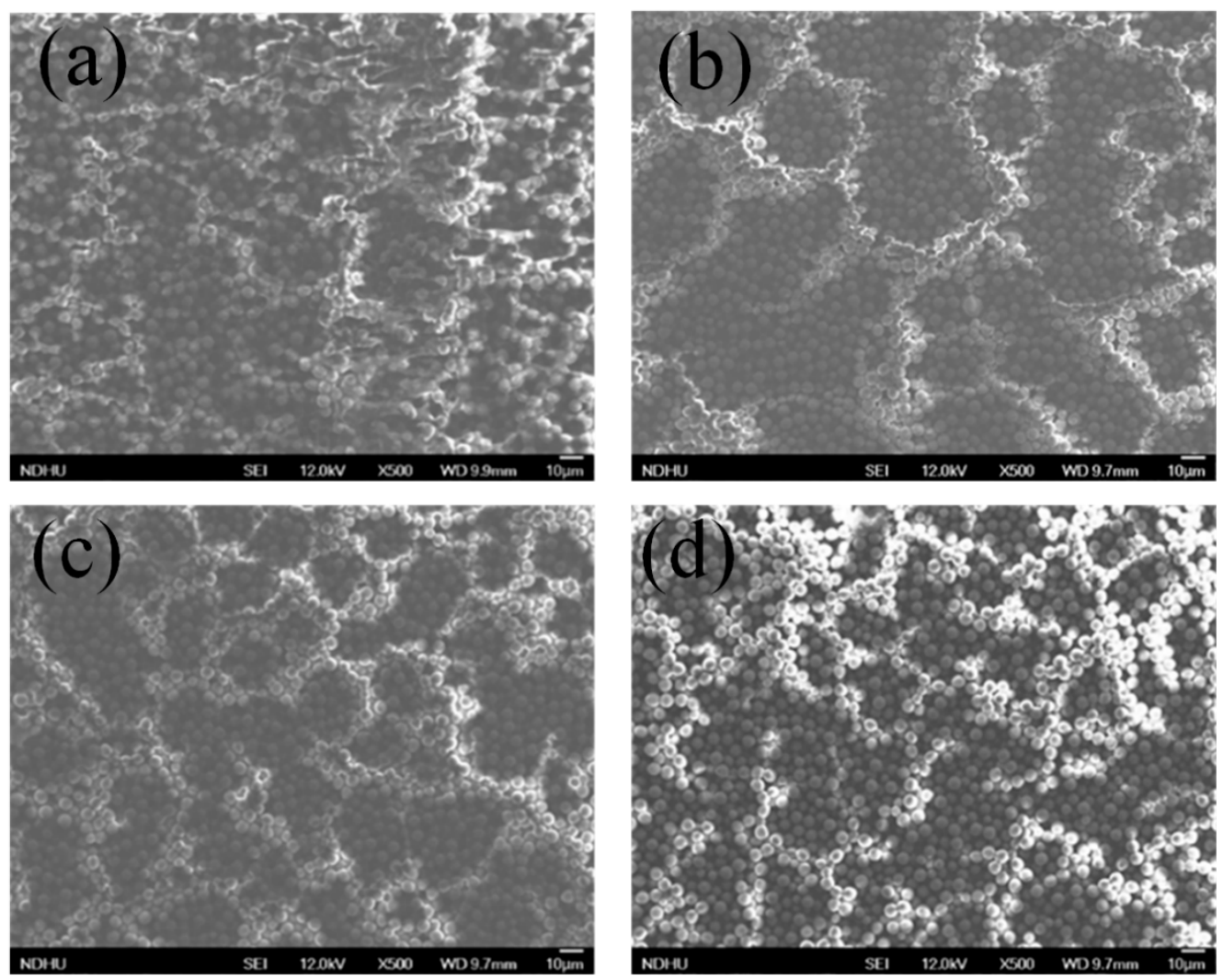

Figure 3. Top-view SEM photograph of the fabricated $\mathrm{SiO}_{2}-\mathrm{PMMA}$ composite film for the $\mathrm{SiO}_{2}$ particle weight percent concentrations of (a) $15 \mathrm{wt} \%$, (b) $20 \mathrm{wt} \%$, (c) $25 \mathrm{wt} \%$ and (d) $35 \mathrm{wt} \%$.

Measurement of the absorption was performed with a micro-Fourier transform infrared spectroscopy with a reflective-type microscope objective with a magnification of $36 \times$. A liquid- $\mathrm{N}_{2}$-cooled $\mathrm{HgCdTe}$ infrared detector was used for the detection of radiation.

\section{Results and Discussion}

The absorption spectrum of the $\mathrm{SiO}_{2}-\mathrm{PMMA}$ composite film is provided in Figure $4 \mathrm{a}$. Black, red, blue, and pink lines represent the absorption spectra of the $15 \mathrm{wt} \%, 20 \mathrm{wt} \%$, $25 \mathrm{wt} \%$, and $35 \mathrm{wt} \% \mathrm{SiO}_{2}-\mathrm{PMMA}$ composite films, respectively. For the radiative cooling application, the spectral range from $8 \mu \mathrm{m}$ to $14 \mu \mathrm{m}$ is of particular concern. In this range, for the $15 \mathrm{wt} \%$ sample, it can be seen that absorption dips at $11.5 \mu \mathrm{m}$, which corresponds to the phonon absorption of $\mathrm{SiO}_{2}$. As the concentration increases, the absorption gradually increases. As shown in Figure 4a, for the $35 \mathrm{wt} \%$ sample, the overall absorption at the transparent window is higher than $90 \%$. For the $40 \mathrm{wt} \%$ and the $45 \mathrm{wt} \%$ samples, the absorption spectrum is very similar to the results of the $30 \mathrm{wt} \%$ sample. This is because the $\mathrm{SiO}_{2}$ particles stack as a multilayer structure as the concentration is higher than $35 \%$. Additional layers of $\mathrm{SiO}_{2}$ particles do not enhance the absorption significantly. Therefore, we did not show the spectrum for the $40 \mathrm{wt} \%$ and the $45 \mathrm{wt} \%$ samples. The spectrum revealed high absorption from $8 \mu \mathrm{m}$ to $14 \mu \mathrm{m}$. According to Kirchhoff's law of thermal radiation, the emissivity at this range is high and is beneficial for radiative cooling. Therefore, the $35 \mathrm{wt} \%$ sample is more suitable as a radiative cooling device as compared to the others. 


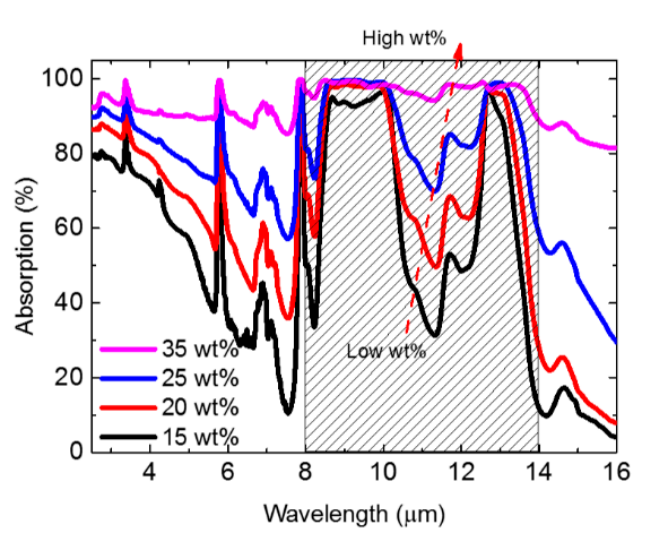

(a)

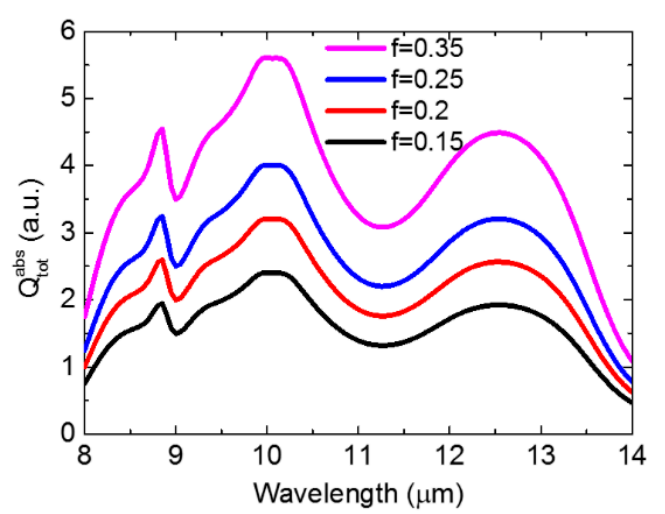

(b)

Figure 4. (a) Absorption spectra of the $\mathrm{SiO}_{2}-\mathrm{PMMA}$ nanocomposite film. Black, red, blue, and pink lines represent the absorption spectrum of $15 \mathrm{wt} \%, 20 \mathrm{wt} \%, 25 \mathrm{wt} \%$, and $35 \mathrm{wt} \% \mathrm{SiO}_{2}-\mathrm{PMMA}$ composite films, respectively. (b) Resultant powers of collective incoherent $\mathrm{SiO}_{2}$ particles calculated by Equation (2). Here, the spectrum that we show is consistent with the atmospheric transparency window, and the material dispersion of $\mathrm{SiO}_{2}$ is based on experimental data. The total powers for $15 \mathrm{wt} \%, 20 \mathrm{wt} \%, 25 \mathrm{wt} \%$, and $35 \mathrm{wt} \% \mathrm{SiO}_{2}-\mathrm{PMMA}$ composite films are depicted in black, red, blue, and pink lines, respectively. The shadow in Figure $4 \mathrm{a}$ indicates the region of transparency window.

Next, to understand the underlying mechanism behind the measured results given in Figure $4 \mathrm{a}$, we calculated the total absorption of $\mathrm{SiO}_{2}$ while taking the total number effect into account. In $[18,19]$, the authors theoretically proved that for a finite-sized object, its thermal emission is proportional to the absorption cross-section. Here, we model $\mathrm{SiO}_{2}$ as a spherical scatterer and investigate its resultant absorption within the atmospheric transparency window. Furthermore, based on exact Mie's scattering theory [20], as well as considering the total number effect, the total absorption cross-section $Q_{\text {tot }}^{a b s}$ can be estimated as follows (see [21]).

$$
Q_{t o t}^{a b s}=N \times Q_{a b s}=\frac{M_{\mathrm{SiO}_{2}}}{\frac{4 \pi}{3} a^{3} \rho} Q_{a b s} \propto f Q_{a b s}
$$

Here, $N$ is the total number of $\mathrm{SiO}_{2}$ particles, and $Q_{a b s}$ is the absorption cross-section by a single $\mathrm{SiO}_{2}$ particle, $M_{\mathrm{SiO}_{2}}$ is mass, $a$ is size, $\rho$ is the mass density of $\mathrm{SiO}_{2}$, and $f$ is weight ratio. This simple expression reveals that increasing the weight ratio of $\mathrm{SiO}_{2}$ could directly enhance the resultant absorption. Figure $4 \mathrm{~b}$ demonstrates that the system with a concentration $35 \mathrm{wt} \%$ can harvest more absorption power in this transparency window, implying the higher emission compared to other schemes. Notably, in the range of $11 \mu \mathrm{m}$, the degradation of absorption stemming from the phonon resonant effect can be also observed in Figure $4 \mathrm{~b}$. In addition, another dip signature of absorption at $9 \mu \mathrm{m}$, shown in Figure 4a, is also evidenced by our calculation results. Our numerical calculation demonstrates good agreement with the experiments shown in Figure 4a.

The directional spectral absorptivity, $\alpha_{d e v}\left(T_{d e v}, \lambda, \theta\right)$, was measured using FTIR. As radiative cooling samples consisting of materials satisfy Lorentz reciprocity [22], the general form of Kirchhoff's law states that the directional spectral emissivity, $\varepsilon_{d e v}\left(T_{\text {dev }}, \lambda, \theta\right)$, is equal to the directional spectral absorptivity. Here, we simply assume that the absorption in the dependence of observing angles is averaged in angles owing to the nature of the microscope measurement setup. Therefore, the emissivity of the $\mathrm{SiO}_{2}-\mathrm{PMMA}$ nanocomposite film as a function of wavelength and observation angle can be obtained based on the measured absorption spectrum shown in Figure 4. Moreover, the change in the emissivity can be ignored within the considered temperature range from $20^{\circ} \mathrm{C}$ to $60^{\circ} \mathrm{C}$. Therefore, in practice, only $\varepsilon_{d e v}\left(T_{d e v}, \lambda, \theta\right)$ at room temperature is measured. Integrating the product of the directional spectral emissivity and temperature-dependent spectral radiance of a 
blackbody, $U_{B}$, which can be calculated from Planck's law, one can obtain the theoretical radiation power density $\left(P_{d e v}\right)$ of the device:

$$
P_{d e v}=\int_{0}^{\pi / 2} \pi \sin 2 \theta d \theta \int_{0}^{\infty} U_{B}\left(T_{d e v}, \lambda\right) \varepsilon_{d e v}\left(T_{d e v}, \lambda, \theta\right) d \lambda
$$

Here, we assume that the heat transfer is based on thermal radiation only. The heat transfer via convection and conduction is ignored. The heat radiates outside the atmospheric transparency window and parasitically absorbs heat radiation from the atmosphere. Under this assumption, the net cooling power density, $P_{\text {net }}$, is given by:

$$
P_{\text {net }}=P_{\text {dev }}-P_{\text {amb }}
$$

where $P_{a m b}$ denotes the radiation power density of the ambient atmosphere, respectively. Similar to the $P_{d e v}$, the $P_{a m b}$ is also a function of the temperature and emissivity of the atmosphere. The emissivity of the atmosphere is taken from reference [23]. The atmospheric transmittance is nearly constant across all angles other than near the horizon [24]. Therefore, we simply assume that the emissivity of the atmosphere is independent of the angles.

The $P_{\text {net }}$ of the $\mathrm{SiO}_{2}-\mathrm{PMMA}$ nanocomposite film as a function of the device temperature $\left(T_{d e v}\right)$ is shown in Figure 5. The ambient temperature is assumed to be $27^{\circ} \mathrm{C}$. Black, red, blue, and pink lines represent the $P_{\text {net }}$ of $15 \mathrm{wt} \%, 20 \mathrm{wt} \%, 25 \mathrm{wt} \%$, and $35 \mathrm{wt} \% \mathrm{SiO}_{2}-\mathrm{PMMA}$ composite films, respectively. As the device temperature increases, $P_{\text {net }}$ almost linearly increases. A higher concentration of $\mathrm{SiO}_{2}$ leads to a higher $P_{\text {net }}$. For $T_{\text {dev }}=60{ }^{\circ} \mathrm{C}, P_{\text {net }}$ of the $35 \mathrm{wt} \%$ sample $\left(920 \mathrm{~W} / \mathrm{m}^{2}\right)$ is 1.67 -fold higher than that of the $15 \mathrm{wt} \%$ sample $\left(580 \mathrm{~W} / \mathrm{m}^{2}\right)$ owing to the high absorption of the high $\mathrm{SiO}_{2}$ concentration.

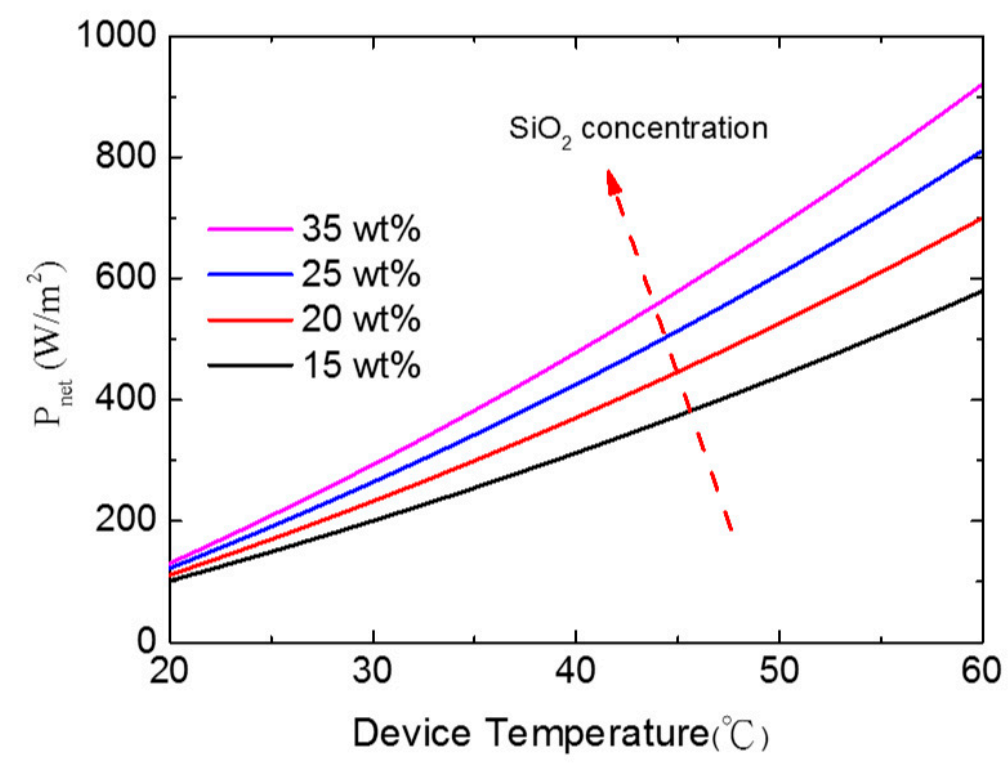

Figure 5. Theoretical net cooling power of the $\mathrm{SiO}_{2}-\mathrm{PMMA}$ nanocomposite film as a function of the radiative cooling device temperature. The ambient temperature is assumed to be $27^{\circ} \mathrm{C}$.

Here, we utilize a hot plate as an ambient heat source. Figure 6a shows the output current of a TEG chip as a function of hot plate temperature. The hot side of the TEG chip is stacked on a hot plate with a temperature higher than the ambient temperature $\left(27^{\circ} \mathrm{C}\right.$, which is a common and recommended indoor temperature). The output current is the short circuit current measured after the chip is placed under thermally equivalent conditions. The black line indicates the output current of a bare TEG chip for reference. The red, blue, pink, and green lines indicate the output current of the TEG stacked with $20 \mathrm{wt} \%, 25 \mathrm{wt} \%, 30 \mathrm{wt} \%$, and $35 \mathrm{wt} \% \mathrm{SiO}_{2}-\mathrm{PMMA}$ sample, respectively, on the cold side. It is demonstrated that the output current can be slightly enhanced from $6 \mathrm{~mA}$ to $10 \mathrm{~mA}$ 
when the hot plate temperature is $50{ }^{\circ} \mathrm{C}$. As mentioned, the phonon absorption of $\mathrm{SiO}_{2}$ is well-matched with the transparent window. According to Wien's displacement law, the thermal emission peak of a blackbody is $8.97 \mu \mathrm{m}$ at $50{ }^{\circ} \mathrm{C}$. This thermal emission peak is also well-matched with the TO phonon absorption of $\mathrm{SiO}_{2}$. Therefore, the proposed cooling device is efficient at this temperature range-for example, a cup of hot coffee and an operating electronic device.

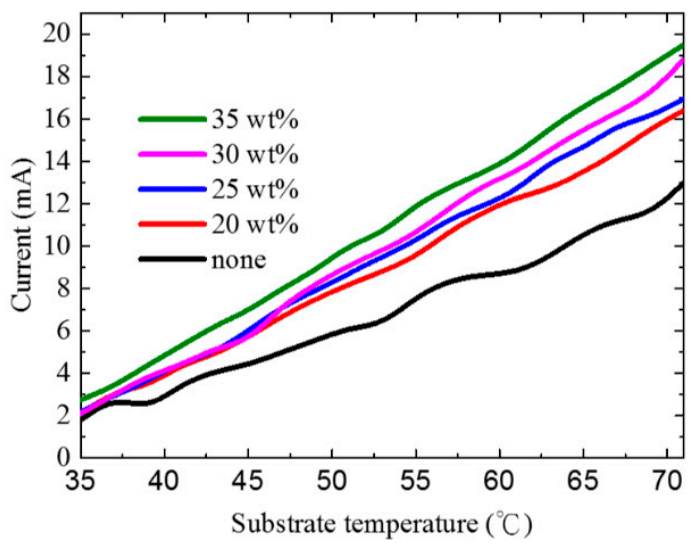

(a)
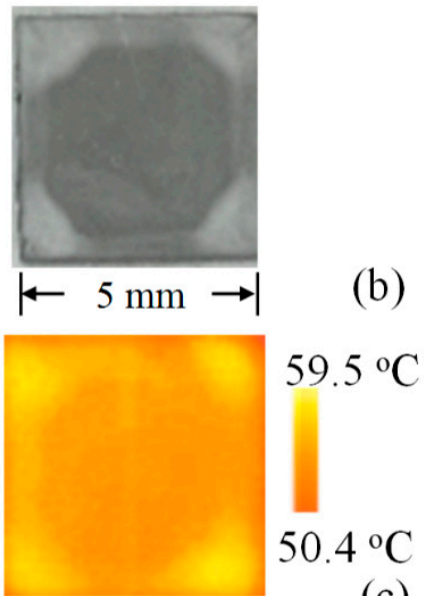

(c)

Figure 6. (a) Enhanced output current of thermoelectric generator (TEG) chip as a function of substrate temperature. Black line is the output current of the bare TEG chip. Red, blue, pink, and green lines represent the TEG stacked with the $15 \mathrm{wt} \%, 20 \mathrm{wt} \%, 25 \mathrm{wt} \%$, and $35 \mathrm{wt} \% \mathrm{SiO}_{2}-\mathrm{PMMA}$ composite films, respectively; (b) Photograph of the $\mathrm{SiO}_{2}-\mathrm{PMMA}$ composite film; (c) Temperature distribution of $\mathrm{SiO}_{2}-\mathrm{PMMA}$ composite film on a heated substrate.

According to the Stefan-Boltzmann Law, the radiation flux increases with increasing substrate temperature. Consequently, $P_{d e v}$ increases with the same trend. As shown in Figure 5, a higher $\mathrm{SiO}_{2}-\mathrm{PMMA}$ concentration leads to a higher emissivity at the window spectral range. Therefore, for a higher substrate temperature, the TEG holds a higher output current. Additionally, a higher-concentration sample holds a higher slope (output current to substrate temperature) owing to the corresponding higher emissivity. Nevertheless, here, we discuss the case in which heat transportation is radiation-dominated. Figure $6 b, c$ present a photograph and the temperature distribution image of the $\mathrm{SiO}_{2}-\mathrm{PMMA}$ composite film on a heated substrate. The temperature distribution image was taken by using an FLIR thermal image camera. In the photograph in Figure 6b, different colors at the edge and at the center of the cooling chip can be observed. The SEM picture reveals that this is because of the stacking layers of the $\mathrm{SiO}_{2}$ microsphere. It stacks more layers of $\mathrm{SiO}_{2}$ at the edge than that at the center. This is a very common condition in spin coating. The temperature distribution image shown in Figure $6 \mathrm{~b}$ reveals that the temperature at the edge is higher than that at the center. In 2018, T. Suichi et al. already proposed a radiative cooler based on $\mathrm{SiO}_{2}-\mathrm{PMMA}$ composites. However, they used three-layer $\mathrm{SiO}_{2}-\mathrm{PMMA}$ with an Al substrate [25]. Our experimental results reveal that the multilayer $\mathrm{SiO}_{2}$ blocks the heat conduction and heat convection. Therefore, the multilayer $\mathrm{SiO}_{2}$ structure suffers from high thermal conduction resistance. At this time, heat transportation is limited by the heat conduction and convection. Therefore, the temperature at the edge of the chip is higher than that at the center.

\section{Conclusions}

In summary, a cost-effective inorganic-polymer nanocomposite, $\mathrm{SiO}_{2}-\mathrm{PMMA}$, is proposed as an effective passive radiative cooling device. The $\mathrm{SiO}_{2}-\mathrm{PMMA}$ film holds a broad transparent spectral range and high emissivity at the transparent window of the 
atmosphere. Additionally, the scattering field of the $\mathrm{SiO}_{2}$ microsphere indicates that the absorption path can be prolonged. The emissivity of the $\mathrm{SiO}_{2}-\mathrm{PMMA}$ can be modified via modifying the concentration of the $\mathrm{SiO}_{2}$ microsphere. Our total absorption calculations of $\mathrm{SiO}_{2}$ based on exact Mie theory offer a good explanation to accompany the experimental results. Although, in our study, the size of the $\mathrm{SiO}_{2}$ scatterer is fixed, we should note that by ensuring a proper system design by tuning the geometry, one can excite the absorption cross-section resonances, further leading to high net cooling power density. Using this photonic-assisted radiative cooling process, the cooling device passively provides a higher temperature gradient. By stacking the cooling device on the cold side of a TEG device, it is demonstrated that the output current of the TEG can be enhanced from $6 \mathrm{~mA}$ to $10 \mathrm{~mA}$ when the hot plate temperature is $50{ }^{\circ} \mathrm{C}$. We demonstrate the harvesting of energy by returning the heat to outer space and generating electric energy, which is a cost-effective and new green technology.

Author Contributions: Conceptualization, C.-M.W. and C.-L.C.; methodology, C.-M.W., C.-L.C., and M.-K.W.; investigation, J.-Y.L., S.-R.W., and Y.-X.L.; writing-original draft preparation, C.-M.W.; writing-review and editing, C.-H.L.; visualization, C.-H.L. All authors have read and agreed to the published version of the manuscript.

Funding: This research was funded by Ministry of Science and Technology, Taiwan, grant number MOST107-2628-E-008-004-MY3 and MOST 109-2124-M-008-002-MY3.

Conflicts of Interest: The authors declare no conflict of interest.

\section{References}

1. Bauer, T. Thermophotovoltaics: Basic Principles and Critical Aspects of System Design; Springer Science \& Business Media: Berlin/Heidelberg, Germany, 2011.

2. Asahi, S.; Teranishi, H.; Kusaki, K.; Kaizu, T.; Kita, T. Two-step photon up-conversion solar cells. Nat. Commun. 2017,8 , 14962. [CrossRef] [PubMed]

3. Bartoli, B.; Catalanotti, S.; Coluzzi, B.; Cuomo, V.; Silvestrini, V.; Troise, G. Nocturnal and diurnal performances of selective radiators. Appl. Energy 1977, 3, 267-286. [CrossRef]

4. Rephaeli, E.; Raman, A.; Fan, S. Ultrabroadband Photonic Structures to Achieve High-Performance Daytime Radiative Cooling. Nano Lett. 2013, 13, 1457-1461. [CrossRef] [PubMed]

5. Gentle, A.R.; Smith, G.B. Radiative Heat Pumping from the Earth using Surface Phonon Resonant Nanoparticles. Nano Lett. 2010, 10, 373-379. [CrossRef] [PubMed]

6. Hossain, M.; Jia, B.; Gu, M. A Metamaterial Emitter for Highly Efficient Radiative Cooling. Adv. Opt. Mater. 2015, 3, 1047-1051. [CrossRef]

7. Zhai, Y.; Ma, Y.; David, S.N.; Zhao, D.; Lou, R.; Tan, G.; Yang, R.; Yin, X. Scalable-manufactured randomized glass-polymer hybrid metamaterial for daytime radiative cooling. Science 2017, 355, 1062-1066. [CrossRef]

8. Wu, S.-R.; Lai, K.-L.; Wang, C.-M. Passive temperature control based on a phase change metasurface. Sci. Rep. 2018, 8, 1-6. [CrossRef]

9. Raman, A.P.; Anoma, M.A.; Zhu, L.; Rephaeli, E.; Fan, S. Passive radiative cooling below ambient air temperature under direct sunlight. Nature 2014, 515, 540-544. [CrossRef]

10. Zhu, L.; Raman, A.P.; Fan, S. Radiative cooling of solar absorbers using a visibly transparent photonic crystal thermal blackbody. Proc. Natl. Acad. Sci. USA 2015, 112, 12282-12287. [CrossRef]

11. Atiganyanun, S.; Plumley, J.B.; Han, S.J.; Hsu, K.; Cytrynbaum, J.; Peng, T.L.; Han, S.M. Effective Radiative Cooling by PaintFormat Microsphere-Based Photonic Random Media. ACS Photonics 2018, 5, 1181-1187. [CrossRef]

12. Chen, W.-H.; Wu, P.-H.; Wang, X.-D.; Lin, Y.-L. Power output and efficiency of a thermoelectric generator under temperature control. Energy Convers. Manag. 2016, 127, 404-415. [CrossRef]

13. Elim, H.I.; Cai, B.; Kurata, Y.; Sugihara, O.; Kaino, T.; Adschiri, T.; Chu, A.-L.; Kambe, N. Refractive Index Control and Rayleigh Scattering Properties of Transparent TiO2Nanohybrid Polymer. J. Phys. Chem. B 2009, 113, 10143-10148. [CrossRef]

14. Lü, C.; Guan, C.; Liu, Y.; Cheng, A.Y.; Yang, B. PbS/Polymer Nanocomposite Optical Materials with High Refractive Index. Chem. Mater. 2005, 17, 2448-2454. [CrossRef]

15. Zhao, B.; Hu, M.; Ao, X.; Chen, N.; Pei, G. Radiative cooling: A review of fundamentals, materials, applications and prospects. Appl. Energy 2019, 236, 489-513. [CrossRef]

16. Ganic, D.; Gan, X.; Gu, M. Three-dimensional evanescent wave scattering by dielectric particles. Optik 2002, 113, $135-141$. [CrossRef]

17. Lin, S.F.; Wang, C.M.; Tsai, Y.L.; Ding, T.J.; Yang, T.H.; Chen, W.Y.; Yeh, S.F.; Chang, J.Y. A model for fast predicting and optimizing the sensitivity of surface-relief guided mode resonance sensors. Sens. Actuators B Chem. 2013, 176, 1197-1203. [CrossRef] 
18. Greffet, J.-J.; Bouchon, P.; Brucoli, G.; Sakat, E.; Marquier, F. Generalized Kirchhoff law. arXiv 2016, arXiv:1601.00312.

19. Kattawar, G.W.; Eisner, M. Radiation from a Homogeneous Isothermal Sphere. Appl. Opt. 1970, 9, 2685-2690. [CrossRef]

20. Bohren, C.F.; Huffman, D.R. Absorption and Scattering of Light by Small Particles; John Wiley \& Sons: Hoboken, NJ, USA, 1998.

21. Lee, J.-Y.; Tsai, M.-C.; Chen, P.-C.; Chen, T.-T.; Chan, K.-L.; Lee, C.-Y.; Lee, R.-K. Thickness Effects on Light Absorption and Scattering for Nanoparticles in the Shape of Hollow Spheres. J. Phys. Chem. C 2015, 119, 25754-25760. [CrossRef]

22. Kruger, M.; Bimonte, G.; Emig, T.; Kardar, M. Trace formulae for non-equilibrium Casimir interactions, heat radiation and heat transfer for arbitrary objects. Phys. Rev. B 2012, 86, 115423. [CrossRef]

23. IR. Transmission Spectra, Gemini Observatory Kernel Description. Available online: http://www.gemini.edu/?q/node/10789 (accessed on 20 November 2016).

24. Bhatia, B.; Leroy, A.; Shen, Y.; Zhao, L.; Gianello, M.; Li, D.; Gu, T.; Hu, J.; Soljačić, M.; Wang, E.N. Passive directional sub-ambient daytime radiative cooling. Nat. Commun. 2018, 9, 1-8. [CrossRef] [PubMed]

25. Suichi, T.; Ishikawa, A.; Hayashi, Y.; Tsuruta, K. Performance limit of daytime radiative cooling in warm humid environment. AIP Adv. 2018, 8, 055124. [CrossRef] 